\title{
MATHEMATICAL MODELING OF HEAT FRICTION CONTACT MASTER BELT WITH THE GUN MOUNT BARREL DURING THE PROCESS OF HIGH-SPEED MOTION
}

\author{
Jaroslav Zezulinsky ${ }^{1,}{ }^{*}$, Anatolyi Guskov ${ }^{1}$, and Konstantin Milevsky ${ }^{1}$ \\ ${ }^{1}$ Novosibirsk State Technical University, Novosibirsk, Russia
}

\begin{abstract}
The friction in the gun mount barrel at sliding speeds of artillery projectile $500-700 \mathrm{~m} / \mathrm{s}$ is not sufficiently studied. The main problem is to increase the efficiency of the master belt with a significant increase of the interaction parameters of the barrel with the projectile. To determine the effect of heating on the change of physical and mechanical properties of the surface layer and friction coefficient on the surface of the master belt were made mathematical modeling of heat transfer.
\end{abstract}

The friction in the gun mount barrel at sliding speeds of artillery projectile $500-700 \mathrm{~m} / \mathrm{s}$ is not sufficiently studied. A distinctive feature of the system "gun mount barrel - artillery projectile" is an intense plastic deformation in the process of formation of the master belt, which provides a seal during high-speed motion of an artillery projectile on the core surface of the gun mount barrel $[1,2,3]$. The main problem is to increase the efficiency of the master belt with a significant increase of the interaction parameters of the barrel with the projectile. It is known that during the motion of the projectile through the gun mount barrel its contact temperature on the surface of the master belt reaches a considerable value, which leads to melting of the surface layers of the master belt material $[4,5,6]$. To determine the effect of heating on the change of physical and mechanical properties of the surface layer and friction coefficient on the surface of the master belt three areas that interact with the surface of the rifling of the gun mount barrel have been selected. They are R1 -field rifling, R2 - fighting line and R3 - the bottom of the rifling (fig. $1 \mathrm{a}, \mathrm{b}, \mathrm{c}$ ), respectively.

\footnotetext{
* Corresponding author: stroncyi@yandex.ru
} 


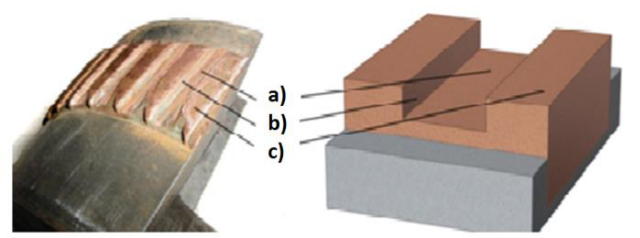

Fig. 1. Areas for the solution of the problem of determining the temperature at the surface contact between the master belt and the barrel.

The surface temperature $\mathrm{T}$ at any point overlapping off the heat source is $[7,8,9]$ :

$$
\mathrm{T}=2 Q(t / \pi k \rho c)^{\frac{1}{2}}
$$

where $\mathrm{t}$ - is the propagation time of the heat source (master belt) through the point of the barrel, which is equal to $\mathrm{t}=\mathrm{B} / \mathrm{V} ; \mathrm{k}, \rho, \mathrm{c}-$ thermal conductivity, density and specific heat of the material half-space.

The source of heat is frictional contact of "master belt - gun mount barrel". Power dissipation in the contact area is $\mathrm{Q}=\mathrm{fpV}$ where $\mathrm{p}$ is the specific pressure.

The temperature at the contact surface is described by the expression:

$$
T_{\max }=2 f P \sqrt{\frac{B / V}{\pi \rho k c}}
$$

To determine the dependence of the speed of projectile on the barrel, the results obtained by the authors were used. The coefficient F of the friction pair "steel - copper" for the initial time is taken as equal to 0.3 . The specific pressure is constant and equals the material fluidity strength of the master belt. According to the theory the "flashpoint" for metals is determined by the melting point. For the material M1 of the model master belt of the projectile, it is equal to $1053{ }^{\circ} \mathrm{C}$, which corresponds to the melting point of $1083^{\circ} \mathrm{C}$ minus the ambient temperature equal $30^{\circ} \mathrm{C}$.

To solve the problem of heat conduction in the master belt material, the solution scope was selected. The Cartesian coordinate system was used. The curvature of the surface was not taken into account, as the diameter of the master belt is much greater than the width of the bottom, field and height of rifling. The origin was located at the intersection of the axis of symmetry of the projection and the matching surface of the master belt with the casing of an artillery projectile.

The heat conduction equation has been solved:

$$
\rho C_{p} \frac{\partial T}{\partial t}=\lambda\left(\frac{\partial^{2} T}{\partial x^{2}}+\frac{\partial^{2} T}{\partial y^{2}}\right),
$$

The initial $(\mathrm{t}=0)$ and boundary conditions are:

$$
\begin{aligned}
& \frac{\partial^{2} T}{\partial x^{2}}=0, \mid \begin{array}{lll}
\mathrm{X}=0,0 \leq \mathrm{Y} \leq Y_{2} & \mathrm{~T}=\mathrm{T}_{R_{4}}(\mathrm{t}) & \mathrm{Y}=Y_{1} \mathrm{X}_{1} \leq \mathrm{X} \leq X_{2} \\
\mathrm{X}=X_{2}, 0 \leq \mathrm{Y} \leq Y_{1} & \mathrm{~T}=\mathrm{T}_{R_{2}}(\mathrm{t}) & \mathrm{X}=X_{1}, \mathrm{Y}_{1} \leq \mathrm{Y} \leq Y_{2}
\end{array} \\
& \frac{\partial T}{\partial x}=0, Y=0,0 \leq \mathrm{X} \leq X_{2} \quad \mathrm{~T}_{2}=\mathrm{T}_{\mathrm{D}_{0}}(\mathrm{t}) \quad \mathrm{Y}=Y_{2}, 0 \leq \mathrm{X} \leq \mathrm{X}_{1}
\end{aligned}
$$

From fig. 2 it is seen that in all areas of contact according to temperature changes depending on the time of projectile motion are identical, but the most intensive temperature 
increase occurred in the initial period of motion of the projectile through the barrel (up to $t$ $=0,023 \mathrm{~s})$ in the area $\mathrm{R} 1$.

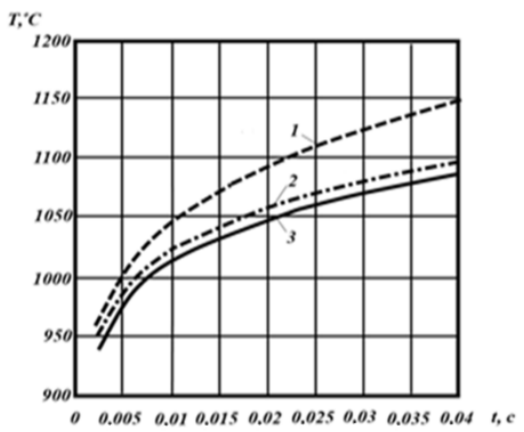

Fig. 2. Temperature variation on the surface areas of master belt during motion of the projectile through gun mount barrel: 1) R1;2) R2 3) R3.

Thus, it is possible to draw the following conclusions:

- Under the action of frictional contact "Barrel - master belt - artillery projectile" is an intensive heating of near-surface deformed layer of the copper master belt of artillery projectile.

- As a result of intensive heating of the surface material of the master belt is partially recrystallized and becomes molten.

- Change of physical and mechanical properties of the master belt material during recrystallization leads to the increased elongation and reduced tensile strength.

- As a result of changes in physical and mechanical properties and the intense heating the transfer of thin layers of copper on the surface of the barrel occurs.

\section{References}

1. A. Gus'kov, Vestnik akademii voennyh nauk (2012)

2. $\quad$ V. Balakin, Trenie i iznos pri vysokih skorostjah skol'zhenija (1980)

3. R. Montgomery, Wear 38, 2 (1976)

4. Jettls, S. Vlijanie teplovyh jeffektov na trenie pri vysokih skorostjah skol'zhenija (1986)

5. A. Gus'kov, K.. Milevskij, E. Slesareva, Izv. Vys. Uch. Zav. Fiz. 56, 6-3 (2013)

6. A. Gus'kov, N. Gorelova, K. Milevskij, A. Sil'chenko, Trudy XIV vseros. Nauch.tehn. Konf. Nauka Prom. Ob. (2013)

7. H. Blok, Proc. Inst. Mech. Eng. 2 (1937)

8. A. Gus'kov, K. Milevskij, N. Chajka, Ja. Zezjulinski, Mezh. nauch. konf. "SibOptika-2015" (2015)

9. A. Gus'kov, Ja. Zezjulinskij, K. Milevskij, E. Nezhivyh, Conf. Nauka. Promysh. Ob. (2015) 